\title{
Pituitary tumour fibroblast-derived cytokines influence tumour aggressiveness
}

\author{
Pedro Marques1, Sayka Barry1, Eivind Carlsen², David Collier¹, Amy Ronaldson', Sherine Awad1, Neil Dorward³, \\ Joan Grieve ${ }^{3}$, Nigel Mendoza4, Samiul Muquit'5 , Ashley B Grossman¹, Frances Balkwill6 and Márta Korbonits ${ }^{1}$
}

${ }^{1}$ Centre for Endocrinology, William Harvey Research Institute, Barts and the London School of Medicine and Dentistry, Queen Mary University of London, London, UK

2Department of Pathology, STHF, Skien, Norway

${ }^{3}$ The National Hospital for Neurology and Neurosurgery, UCLH, NHS Trust, London, UK

${ }^{4}$ Department of Neurosurgery, Charing Cross Hospital, Imperial College, London, UK

${ }^{5}$ Department of Neurosurgery, Derriford Hospital, Plymouth, UK

${ }^{6}$ Barts Cancer Institute, Barts and the London School of Medicine and Dentistry, Queen Mary University of London,

Charterhouse Square, London, UK

Correspondence should be addressed to M Korbonits: m.korbonits@qmul.ac.uk

\begin{abstract}
Tumour-associated fibroblasts (TAFs) are key elements of the tumour microenvironment, but their role in pituitary neuroendocrine tumours (PitNETs) has been little explored. We hypothesised that TAF-derived cytokines may play a role in tumour aggressiveness and that their release can be inhibited by somatostatin analogues. TAFs were isolated and cultured from 16 PitNETs (11 clinically non-functioning tumours and 5 somatotropinomas). The fibroblast secretome was assessed with a 42-plex cytokine array before and after multiligand somatostatin receptor agonist pasireotide treatment. Angiogenesis and epithelial-to-mesenchymal transition pathway assessment included CD31, E-cadherin and ZEB1 expression. GH3 cells treated with TAF- or skin fibroblastconditioned medium were assessed for migration, invasion and cell morphology changes. PitNET TAFs secreted significant amounts of cytokines including CCL2, CCL11, VEGF-A, CCL22, IL-6, FGF-2 and IL-8. TAFs from PitNETs with cavernous sinus invasion secreted higher IL-6 levels compared to fibroblasts from non-invasive tumours $(P=0.027)$. Higher CCL2 release from TAFs correlated with more capillaries $(r=0.672, P=0.004)$, and TAFs from PitNETs with a higher Ki-67 tended to secrete more CCL2 $(P=0.058)$. SST1 is the predominant somatostatin receptor in TAFs, and pasireotide decreased TAF-derived IL-6 by $80 \%(P<0.001)$ and CCL2 by $35 \%(P=0.038) . \mathrm{GH} 3$ cells treated with TAF-conditioned medium showed increased migration and invasion compared to cells treated with skin fibroblast-conditioned medium, with morphological and E-cadherin and ZEB1 expression changes suggesting epithelial-to-mesenchymal transition. TAF-derived cytokines may increase PitNET aggressiveness, alter angiogenesis and induce epithelial-to-mesenchymal transition changes. Pasireotide's inhibitory effect on TAF-derived cytokines suggest that this effect may play a role in its anti-tumour effects.
\end{abstract}

\author{
Key Words \\ - pituitary neuroendocrine \\ tumour \\ - tumour microenvironment \\ - tumour-associated \\ fibroblasts \\ - cytokine \\ - pasireotide
}

2019 Society for Endocrinology Published by Bioscientifica Ltd. Printed in Great Britain
Endocrine-Related Cancer (2019) 26, 853-865 


\section{Introduction}

The great majority of pituitary neuroendocrine tumours (PitNETs) are benign, although they can cause significant burden to patients due to mass effects, invasion and/or due to excessive or low hormone secretion (Di Ieva et al. 2014, Molitch 2017).

Tumour behaviour is greatly influenced by the surrounding extracellular matrix, immune cells, endothelial cells, pericytes and fibroblasts, collectively called the tumour microenvironment, via intensive crosstalk with neoplastic cells (Bissell \& Radisky 2001, Balkwill et al. 2012). This interaction, mediated by a complex network of cytokines, chemokines and growth factors, plays a crucial role in tumour initiation, progression, angiogenesis, invasion and metastasis (Bissell \& Radisky 2001, Balkwill 2012, Balkwill \& Mantovani 2012, Balkwill et al. 2012, Grizzi et al. 2015).

Fibroblasts are the most abundant cells in connective tissues, playing a key rolein tissuestructureand homeostasis. Quiescent fibroblasts undergo activation in tumours, often then termed as tumour-associated fibroblasts (TAFs) (Cirri \& Chiarugi 2012, Shiga et al. 2015). TAFs are an important source of cytokines and growth factors which contribute to their pro-tumoural effects, influencing proliferation, invasiveness, angiogenesis, epithelial-to-mesenchymal transition (EMT) and extracellular matrix remodelling by promoting expression of collagen, hyaluronan, fibronectin and matrix proteases (De Boeck et al. 2013, MoatassimBillah et al. 2016, Shiga et al. 2015). In numerous cancers, such as breast, prostate, lung, gastric and pancreatic cancer (Cirri \& Chiarugi 2012, Liao et al. 2013, Duluc et al. 2015, Shiga et al. 2015, Moatassim-Billah et al. 2016, Wu et al. $2017 b$ ), TAFs are associated with increased aggressiveness and poor outcome. The role of PitNET-associated TAFs in the behaviour of pituitary tumours remains unknown.

First-generation (octreotide and lanreotide activating mainly somatostatin receptor subtype 2, SST2) and secondgeneration (pasireotide activating SST1, SST2, SST3 and SST5) somatostatin analogues have been effectively used in the management of many types of PitNETs (IbanezCosta \& Korbonits 2017, Gunther et al. 2018). In addition to their inhibitory effects on tumour cells (Ibanez-Costa \& Korbonits 2017), they may also display an indirect anti-tumoural effect by targeting cells of the tumour microenvironment, as shown in a recent study where the anti-proliferative, anti-invasive and anti-metastatic effects of pasireotide were reported to be mediated through the pharmacological inhibition of stromal pancreas cancerassociated fibroblasts (Moatassim-Billah et al. 2016).
We therefore hypothesised that PitNET fibroblastderived cytokines may play a role in pituitary tumour aggressiveness and that their release could be inhibited by somatostatin analogues.

\section{Materials and methods}

\section{Isolation and primary cell culture of fibroblasts from human PitNETs}

Fresh human PitNET tissues were obtained at the time of transsphenoidal surgery from patients with clinically non-functioning PitNETs (NF-PitNETs, $n=11$ ) and acromegaly $(n=5)$ (Table 1$)$. This study was approved by the Cambridge East Research Ethics Committee (MREC No. 06/Q0104/133), and samples were obtained after written informed consent. Fresh tumour tissue was collected in high glucose Dulbecco's Modified Eagle's Medium (DMEM) (Sigma, cat. no. D6429) supplemented with 10\% heat-inactivated foetal bovine serum (FBS) (Gibco, cat. no. 16000044) and 0.5\% gentamicin (Sigma, cat. no. G1397), and cultured on the same operation day. Following rinsing three times in magnesium and calciumfree phosphate buffered saline (PBS) (Sigma, cat. no. D8537), samples were cut into small pieces and incubated in 1:10 diluted Trypsin-EDTA 0.05\% Phenol Red (Gibco, cat. no. 25300054) for $45 \mathrm{~min}$ at $37^{\circ} \mathrm{C}$ with frequent pipetting allowing effective cell dispersion. Trypsin digestion was stopped by transfer to complete medium, and after $10 \mathrm{~min}$ of sedimentation cell suspensions containing pituitary tumour cells were aspirated to a separate tube. PitNET-derived TAFs were obtained using the so-called outgrowth method (Moatassim-Billah et al. 2016): undigested debris pieces were placed in a scratched uncoated six-well plate and incubated at $5 \% \mathrm{CO}_{2}$ at $37^{\circ} \mathrm{C}$ in $0.5 \%$ gentamicin and 10\% FBS DMEM. Plates were examined under the microscope daily, and medium was replaced three times a week. After 2-3 weeks, fibroblasts migrated out of the debris and, when confluent (about 4 weeks later), were transferred to uncoated culture flasks. No other cells, including pituitary tumour cells, were seen at this time.

Fibroblast supernatants for cytokine assessment were collected from $5 \times 10^{5}$ early passage fibroblasts seeded in T75 culture flasks and grown in complete medium to $90 \%$ of confluence. Following washes, and culture in $6 \mathrm{~mL}$ serum-free medium, supernatant was collected after $24 \mathrm{~h}$ and stored at $-80^{\circ} \mathrm{C}$ until assay. After $48 \mathrm{~h}$ in complete medium, cells were treated with $10^{-7} \mathrm{M}$ pasireotide
C) 2019 Society for Endocrinology Published by Bioscientifica Ltd. Printed in Great Britain 
Table 1 Baseline clinicopathological features of the 16 patients with PitNETs from whom the tumour-associated fibroblasts were isolated.

\begin{tabular}{|c|c|}
\hline Clinicopathological features & $n=16$ \\
\hline \multicolumn{2}{|l|}{ Gender $(n(\%))$} \\
\hline Male & $11(68.8 \%)$ \\
\hline Female & $5(31.2 \%)$ \\
\hline Age at first symptoms (years) (mean \pm S.D.) & $50.1( \pm 13.9)$ \\
\hline Age at diagnosis (years) (mean \pm S.D.) & $51.8( \pm 13.6)$ \\
\hline \multicolumn{2}{|l|}{ Clinical diagnosis $(n(\%))$} \\
\hline Acromegaly & $5(31.2 \%)$ \\
\hline Non-functioning PitNET & $11(68.8 \%)$ \\
\hline Headache at diagnosis ( $n(\%))$ & $8(50.0 \%)$ \\
\hline Visual impairment at diagnosis ( $n(\%))$ & $9(56.3 \%)$ \\
\hline Hypopituitarism at diagnosis $(n(\%))$ & $7(43.8 \%)$ \\
\hline $\begin{array}{l}\text { Number of pituitary deficiencies at diagnosis } \\
\text { (mean } \pm \text { S.D.) }\end{array}$ & $0.9( \pm 1.2)$ \\
\hline Macroadenoma $(n(\%))$ & $16(100.0 \%)$ \\
\hline Suprasellar extension $(n(\%))$ & $16(100.0 \%)$ \\
\hline Cavernous sinus invasion $(n(\%))$ & $6(37.5 \%)$ \\
\hline Ki-67 $\geq 3 \%(n(\%))$ & $3(18.8 \%)$ \\
\hline
\end{tabular}

(Novartis Pharma) in $6 \mathrm{~mL}$ serum-free medium for $24 \mathrm{~h}$, and supernatants collected for cytokine array. Conditioned medium from TAFs and normal skin fibroblasts (isolated from skin biopsies of healthy young subjects, one male and one female) were generated similarly but in complete medium conditions.

Cytokine arrays on TAF supernatants were performed by Eve Technologies (Calgary, Alberta, Canada), according to their protocol using the Multiplexing Analyser BioPlex $^{\text {TM }} 200$ system (Bio-Rad Laboratories, Inc.) and the human cytokine/chemokine array with IL-18 (HD42) kit (Millipore). This array measured 42 different cytokines, chemokines and growth factors in the same sample: G-CSF, GM-CSF, IFN $\alpha 2$, IFN $\gamma$, IL-1 $\alpha$, IL-1 $\beta$, IL-1ra, IL-2, IL-3, IL-4, IL-5, IL-6, IL-7, IL-8, IL-9, IL-10, IL-12(p40), IL-12(p70), IL-13, IL-15, IL-17A, IL-18, CXCL1, CXCL10, CCL2, CCL3, CCL4, CCL5, CCL7, CCL22, CX3CL1, CCL11, sCD40L, Flt-3L, PDGF-AA, PDGF-BB, TGF- $\alpha$, TNF- $\alpha$, TNF- $\beta$, VEGF-A, EGF, FGF-2.

\section{Cell line culture and in vitro functional studies}

GH3 cells (rat somatomammotroph cell line, European Collection of Authenticated Cell Cultures) were cultured in high glucose DMEM supplemented with 10\% FBS and $0.5 \%$ gentamicin at $5 \% \mathrm{CO}_{2}$ at $37^{\circ} \mathrm{C}$. Invasion assays were carried out using the BioCoat Matrigel Invasion Chambers with $8 \mu \mathrm{m}$ pores (24-well insert; BD Biosciences, CA, USA, cat. no. 354480). Invasion chambers were hydrated for $2 \mathrm{~h}$ with $500 \mu \mathrm{L}$ of serum-free medium at $37^{\circ} \mathrm{C}$. After Matrigel rehydration, $750 \mu \mathrm{L}$ of TAF-conditioned medium, skin fibroblast-conditioned medium or complete medium was added to the lower chamber as chemoattractant and $2.5 \times 10^{4} \mathrm{GH} 3$ cells in $500 \mu \mathrm{L}$ serum-free medium were added to the upper chambers and incubated at $37^{\circ} \mathrm{C}$. After $72 \mathrm{~h}$, invading cells through the Matrigel membrane were fixed in 100\% methanol and stained with $2 \%$ Giemsa blue (Sigma-Aldrich, cat. no. G5637-5G). The total number of invading cells per chamber were counted, and normalised to invading cells towards complete medium. Migration was evaluated by Transwell BioCoat Migration insert plates with $8 \mu \mathrm{m}$ pores (24-well insert; Corning Fisher Scientific, cat. no. 354578) following a similar protocol as described for the invasion assay. Migration and invasion studies were repeated at least three times in duplicate.

Changes in GH3 cell morphology were assessed as previously described (Barry et al. 2019). In short, area (area of selection in calibrated square units, $\mu \mathrm{m}^{2}$ ); perimeter $(\mu \mathrm{m})$; Feret's diameter (longest distance between any two points along selection boundary); circularity (representing perimeter smoothness, $4 \pi \times$ (Area) (Perimeter) ${ }^{2}$, with value of 1 indicating a perfect circle and value close to 0 indicating elongated shape); roundness (representing shape, $4 \times($ Area $) / \pi \times(\text { Major axis) })^{2}$ with value of 1 for a circle and 0 for very elongated shapes) and solidity (value of 1 indicating more stiffness and less deformable cells, a parameter indicating cells undergoing EMT (Pasqualato et al. 2013)) were measured using ImageJ software (National Institutes of Health, USA). Five images were taken per treatment condition at $40 \times$, and 15 cells were measured per image; hence, 75 cells were analysed per experiment, with a minimum of three repeat experiments performed.

\section{Immunocytochemistry}

Fibroblasts or GH3 cells $\left(5 \times 10^{4}\right)$ were plated on $15 \mathrm{~mm}$ coverslips placed in 12-well plates. After overnight attachment, fibroblasts were fixed and stained, while GH3 cells were further treated for $24 \mathrm{~h}$. Cells were fixed in $4 \%$ paraformaldehyde for $15 \mathrm{~min}$ at room temperature, following washes with PBS, cells were permeabilised with $0.1 \%$ Triton $\mathrm{X}-100$ in PBS for $5 \mathrm{~min}$ at $4^{\circ} \mathrm{C}$. Cells were washed and blocked in 1\% BSA for $30 \mathrm{~min}$ at room temperature, and then incubated with the following primary antibodies: anti-vimentin (1:100; Abcam, cat. no. Ab16700), anti- $\alpha$-smooth muscle actin ( $\alpha \mathrm{SMA})$ (1:500; Sigma-Aldrich, cat. no. A5228), anti-actin (Molecular Probes, 2 drops/mL; cat. no. R37110), E-cadherin (1:50; BD Biosciences, cat. no. 610181) and ZEB1 (1:50; Santa Cruz Biotechnology, cat. no. H-102: sc-25388). 
After washing, the cells were incubated for 30 min with secondary antibodies conjugated with fluorochromes (Alexa Fluor 568-conjugated goat anti-mouse IgG, Alexa Fluor 488-conjugated donkey anti-mouse IgG and Alexa Fluor 488-conjugated donkey anti-rabbit IgG; 1:1000; Molecular Probes, Invitrogen). Coverslips with stained cells were mounted with Fluoroshield with DAPI mounting medium (Sigma, cat. no. F6057). Stained slides were visualised on a confocal microscope LSM 880 Zeiss and images taken at $63 \times$ magnification. E-cadherin and ZEB1 fluorescent intensities were quantified using the software Carl Zeiss Zen Blue Edition version 2.3.

\section{Immunohistochemical analysis and evaluation}

Immunohistochemical staining was performed on $4 \mu \mathrm{m}$ paraffin-embedded tissue sections using Ventana DAB Map Discovery System (Ventana, Illkirch, France). Slides were deparaffinised in xylene and dehydrated in alcohol to PBS, and then processed for antigen retrieval for $30 \mathrm{~min}$ with cell conditioning solution CC1 (Ventana), which is a Tris base buffer $(\mathrm{pH} \sim 9)$. After blocking with Blocker D solution (Ventana), the sections were incubated for $60 \mathrm{~min}$ with the primary antibodies (anti-vimentin, DAKO M7020, dilution 1:1000; anti-E-cadherin, BD Biosciences 610181, dilution 1:50; anti-ZEB1, Santa Cruz Biotechnology H-102:sc-25388, dilution 1:50; anti-CD31, DAKO M0823, dilution 1:100), and then with the universal secondary antibody (Ventana) for $20 \mathrm{~min}$. Slides were counterstained with haematoxylin. Negative controls with omission of the primary antibody were used. Stained slides were scanned with Pannoramic Scanner (3DHISTECH, Budapest, Hungary) and analysed with Pannoramic Viewer Software (3DHISTECH, Budapest, Hungary). E-cadherin and ZEB1 immunoreactivities were measured semi-quantitatively by an experienced pathologist, blinded to the diagnosis or clinicopathological features of each case, on the basis of both the extent and intensity of the immunoreactivity. The extent of immunoreactivity was scored according to the percentage of stained cells in relation to the entire section as $(0$ points for no staining, 1 point for less than $20 \%, 2$ points for $20-50 \%$ and 3 points for more than $50 \%$ of the cells). Staining intensity was graded on a $0-3$ scale 0 (no staining), 1 (weak), 2 (moderate) and 3 (strong). Sum of extent and intensity scores was used as final staining score. Vessels, stained for the endothelial marker CD31, were counted manually in 3-5 different $20 \times$ magnification fields, allowing the estimation of microvessel density (number of vessels per high power field (HPF)), and the vessels' contour was manually traced using the ImageJ software to obtain an estimation of the total microvessel area $\left(\mu \mathrm{m}^{2} / \mathrm{HPF}\right)$, as previously described (Takano et al. 2014).

\section{Quantitative real-time polymerase chain reaction (RT-qPCR)}

RNA from TAFs was extracted using Qiagen's RNeasy micro kit (cat. no. 74004) according to the manufacturer's protocol in order to examine the expression of somatostatin receptor subtypes. RNA samples were assessed by NanoDrop ND-1000 spectrophotometer (NanoDrop Technologies). cDNA was synthesised from $1 \mu \mathrm{g}$ of RNA using the High-Capacity cDNA RT Kit (Thermofisher Scientific) following the manufacturer's protocol. RT-qPCR reactions were prepared using Brilliant III Ultra-Fast SYBR Green QPCR Master Mix (Agilent Technologies): $10 \mathrm{ng}$ of cDNA $(2 \mu \mathrm{L})$ and Master Mix (10 $\mu \mathrm{L}$ MM Brilliant III SYBR Green PCR, $0.3 \mu \mathrm{L}$ of each forward and reverse primers 10 $\mu \mathrm{M}$, and 7.4 $\mu \mathrm{L}$ nuclease-free water) per reaction. Loaded qPCR 96-well plates run in the Thermal Cycler with MxPro software (Agilent) using the following two-step programme: pre-incubation $3 \mathrm{~min}$ at $95^{\circ} \mathrm{C}$, and then 40 cycles of $20 \mathrm{~s}$ at $95^{\circ} \mathrm{C}$ and $20 \mathrm{~s}$ at $60^{\circ} \mathrm{C}$. Cycle threshold (Ct) values were analysed with standard curve quantification method. Target gene expression was normalised to GAPDH expression used as internal control. Dissociation curves were obtained for each gene, where a single peak was observed. Primers sequence (Sigma-Aldrich) were as follows: SST1 sense 5'-CACATTTCTCATGGGCTTCCT-3', reverse 5'-ACAAACACCATCACCACCATC-3'; SST2 sense 5'-GGCATGTTTGACTTTGTGGTG-3', reverse 5'-GTCTCA TTCAGCCGGGATTT-3'; SST3 sense 5'-TGCCTTCTTTGG GCTCTACTT-3', reverse 5'-ATCCTCCTCCTCAGTCTTC TCC-3'; SST4 sense 5'-TGTGCTACCTGCTCATCGTG-3', reverse 5'-GCTGGTCACGAAGAGGTTCA-3'; SST5 sense 5'-CTGGTGTTTGCGGGATGTT-3'; reverse 5'-GAAGCTCT GGCGGAAGTTGT-3'; GAPDH sense 5'-TGCACCACCAA CTGCTTAG-3'; reverse 5'-GGATGCAGGGATGATGTTC-3'.

\section{Statistical analysis}

Statistical analyses were carried out using the SPSS statistical software version 20 (IBM) and GraphPad version 6 (Prism). The Mann-Whitney $U$ test, one-way or two-way ANOVA tests with post hoc comparison tests were applied as appropriate. Correlations between continuous variables were determined by the Pearson correlation coefficient $r$. $P$ values $<0.05$ were considered significant.
(C) 2019 Society for Endocrinology Published by Bioscientifica Ltd. Printed in Great Britain 


\section{Results}

\section{Detection and in vitro isolation of PitNET-derived tumour-associated fibroblasts}

Vimentin-positive TAFs were identified in PitNETs in the intra-tumoural area and in a rim of fibrous connective tissue, probably representing the tumour pseudo-capsule (Jagannathan et al. 2009, Taylor et al. 2018) (Fig. 1A, B, C and $\mathrm{D})$. Isolated TAFs showed spindle-shaped morphology (Fig. 1E and F), stained for actin and vimentin in all TAFs, with some also expressing $\alpha \mathrm{SMA}$ (Fig. $1 \mathrm{G}$ and $\mathrm{H}$ ), suggesting that only some TAFs display an active phenotype. TAF supernatants and conditioned medium was generated from this mixed TAF population (i.e. $\alpha$ SMA-positive and $\alpha$ SMAnegative TAFs). The morphology of TAFs differed from the appearance of skin fibroblasts from healthy individuals (Fig. 1I and J), as they displayed a more prominent spindlelike shape with several cell projections and being more irregularly distributed in the culture flask surface.

\section{TAF secretome may determine increased aggressiveness of PitNETs}

We hypothesised that TAFs, as a relevant source of cytokines and growth factors, would influence PitNET invasiveness. To address this, we established cultures of TAFs from 16 human PitNETs (clinicopathological patients features shown in Table 1), and then we assessed their cytokine secretome (Table 2 and Supplementary Table 1, see section on supplementary data given at the end of this article). The most highly secreted cytokines/growth factors by TAFs were CCL2, CCL11, VEGF-A, CCL22, IL-6, FGF-2 and IL-8 (Table 2). TAF secretomes from NF-PitNETs and somatotropinomas did not differ significantly (Table 2 ). TAF-derived IL-6 levels were higher in the subgroup of PitNETs with cavernous sinus invasion in comparison to non-invasive PitNETs $(72.7 \pm 10.7$ vs $43.9 \pm 6.3 \mathrm{pg} / \mathrm{mL}$; $P=0.027)$, while there was a trend $(P=0.058)$ for TAFs isolated from PitNETs with a higher Ki-67 proliferation index to secrete more CCL2 (Fig. 2). CCL2 secretion was higher in TAFs derived from females than males ( $6698 \pm 1831$ vs $3918 \pm 220 \mathrm{pg} / \mathrm{mL} ; P=0.04$ ), but there were no gender differences regarding the other cytokines. CCL2 secretion was not dependent on age or the females' pre or postmenopausal status. The presence of headache, hypopituitarism or visual impairment was not associated with differences in TAF cytokine release (data not shown). Levels of TAF-derived CCL2, a chemokine with known angiogenic functions (Yadav et al. 2010, Yoshimura 2017), were positively correlated with microvessel area
( $r=0.672 ; P=0.004)$ suggesting a possible role in PitNET angiogenesis (Supplementary Table 2). Platelet-derived growth factor (PDGF)-AA levels were negatively correlated with E-cadherin expression, indicating a possible role for the TAF secretome in promoting EMT by downregulating E-cadherin (Supplementary Table 2).

\section{TAF-conditioned medium increases invasiveness, migration and induces an EMT-like phenotype in GH3 cells}

To study the effects of TAF-derived factors in pituitary tumour cells, in the absence of an appropriate human pituitary tumour cell line, we assessed the morphology, migration, invasion and EMT activation of GH3 cells in response to TAF-conditioned medium or skin fibroblastconditioned medium. GH3 cells showed significantly higher migration and invasion towards TAF-conditioned medium compared to complete medium, but not towards normal skin fibroblast-conditioned medium (Fig. 3). Skin fibroblasts were not able to increase invasion, while TAF-conditioned medium led to an 11-fold increased invasiveness in comparison to complete medium (Fig. 3). TAF-conditioned medium, but not skin fibroblastconditioned medium, induced EMT-like morphological changes in GH3 cells, leading to a significant increase in cell area, perimeter and Feret's diameter, with decreased solidity, roundness and circularity (Fig. 4). These changes result in larger cells with elongated shape which are more deformable and have better ability to migrate and invade in line with the results in the migration and invasion assays (Fig. 3). These morphological changes were accompanied by granular actin staining with prominent stress fibres and spikes, characteristic of EMT-like cytoskeletal changes (McKayed \& Simpson 2013), while untreated GH3 cells showed actin distributed in a cortical ring (Fig. 4).

TAF-conditioned medium induced EMT in GH3 cells, significantly decreasing E-cadherin and increasing nuclear ZEB1 expression, while untreated GH3 cells show strong E-cadherin with membranous localisation but also in the cytoplasm as well as low nuclear ZEB1 expression (Fig. 5). EMT induction, in line with increased invasion, migration and altered cell shape, suggest that TAF-derived factors interact with pituitary tumour cells influencing their behaviour and invasiveness.

\section{Pasireotide inhibits cytokine secretion from TAFs}

To investigate whether somatostatin analogues affect the TAF cytokine secretome, we first determined SST mRNA 


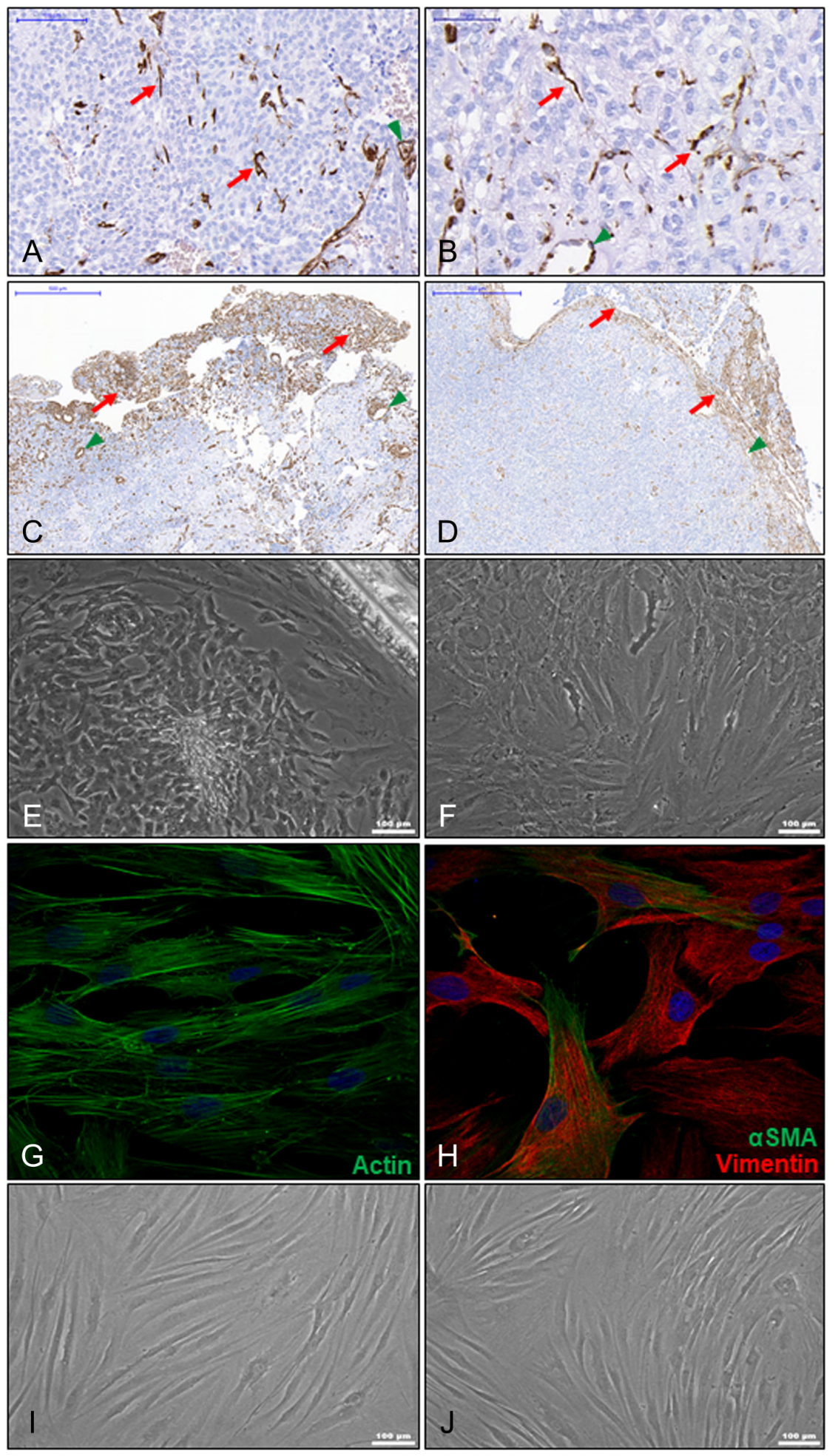

\section{Figure 1}

Immunohistochemical detection and in vitro isolation of PitNET-derived tumour-associated fibroblasts. (A, B, C and D) Vimentin immunostain of PitNETs shows positive staining in spindleshaped and long cells with cytoplasmic projections (red arrows), located in the intratumoural areas ( $A$ and $B$ ) but also in a rim of fibrous connective tissue probably representing the tumour pseudo-capsule (C and D). Vimentin staining is also positive in endothelial cells, distinguishable from fibroblasts by their morphology and localisation in vessels lumen (green arrowheads). Representative photographs at different magnifications are shown (A, 20x; B, 40x; C, 5x; D, 5×). (E and F) TAFs isolated in vitro after migrating out from a debris tissue piece (E) and after reaching confluency in cell culture flasks (F). (G and H) Immunofluorescent staining for actin $(\mathrm{G})$ and for vimentin (red) and $\alpha \mathrm{SMA}$ (green) with vimentin expression seen in all TAFs, whereas $\alpha S M A$ expression seen in many but not all TAFs $(H)$, suggesting that only some TAFs have an active phenotype (63x). (I and J) Morphological appearance of dermal fibroblasts from 2 different healthy individuals, having a less prominent spindle-like shape with shorter projections and being more regularly distributed in the culture flask surface. expression in TAFs. SST1 is the predominant receptor in PitNET-derived TAFs (Fig. 6), similar to pancreas cancerassociated fibroblasts (Duluc et al. 2015, MoatassimBillah et al. 2016), while SST5 and SST2 expression was minimal. SST mRNA expression did not differ between
NF-PitNET-derived TAFs and somatotropinoma-derived TAFs (data not shown).

As the TAFs expressed SST1, we selected pasireotide $\left(10^{-7} \mathrm{M}\right)$ treatment (Duluc et al. 2015, Moatassim-Billah et al. 2016) to assess TAFs responses. Pasireotide treatment 
significantly decreased IL-6 release by $80 \%(P<0.001)$ and CCL2 by $35 \%(P=0.038)$, while the other factors showed a trend for reduction but no statistically significant change (Fig. 7A and Supplementary Table 1). IL-6 secretion was reduced in all the 16 TAFs treated with pasireotide, while CCL2 decreased in 10 out of the 16 cases (62.5\%) (Fig. 7B).

\section{Discussion}

TAFs determine tumour initiation, proliferation, invasiveness and clinical outcomes for many types of tumour (Cirri \& Chiarugi 2012, Shiga et al. 2015), but their role in PitNETs remains unknown. Our data suggest that PitNET-derived TAFs are a source of cytokines which may impact on tumour behaviour. Of the cytokines studied, IL-6 and CCL2 emerged as possible mediators of PitNET invasiveness. Furthermore, the effect of pasireotide on TAF cytokine secretion suggest that its beneficial effect may at least partly be mediated via inhibition of TAFs, in addition to any direct effect on pituitary tumour cells (MoatassimBillah et al. 2016, Ibanez-Costa \& Korbonits 2017).

TAFs are components of the tumour microenvironment in different tumours, including in PitNETs (Tofrizal et al. 2016), and these cells are active sources of cytokines and growth factors (Cirri \& Chiarugi 2012, De Boeck et al. 2013, Shiga et al. 2015). We found highly secreted

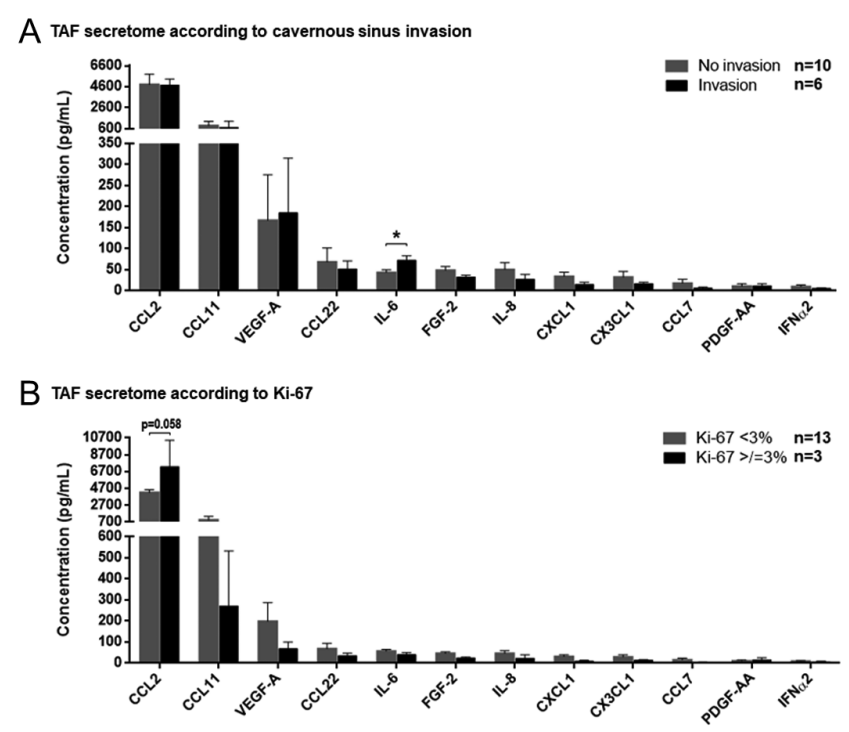

Figure 2

Tumour-associated fibroblasts (TAFs) cytokine secretome according to the presence/absence of cavernous sinus invasion (A) and to Ki-67 index (B). Data are shown as mean concentration $(\mathrm{pg} / \mathrm{mL}) \pm$ S.E.M. for the top 12 secreted cytokines/chemokines/growth factors. *, $<0.05$ (Mann-Whitney $U$ test). 
A Matrigel Invasion Assay
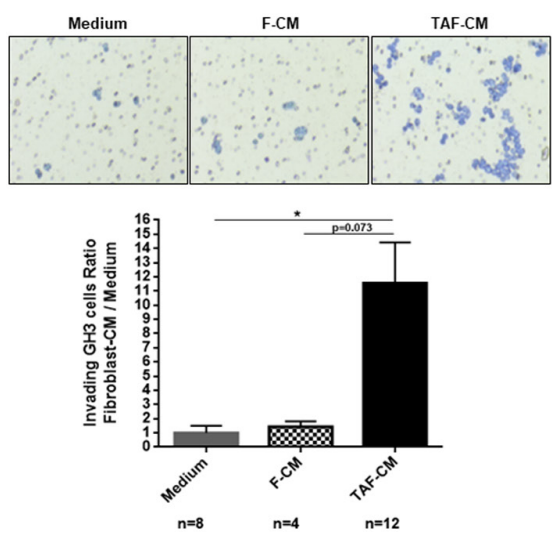

B Transwell Migration Assay
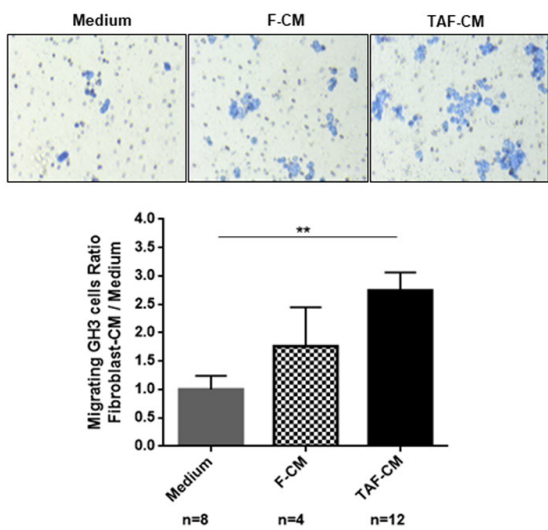

Figure 3

Matrigel-coated chamber invasion assays ( $A$ ) and transwell migration assays (B) performed on GH3 cells towards complete medium, tumourassociated fibroblasts-conditioned medium (TAF-CM) and conditioned medium from dermal fibroblasts from healthy individuals (F-CM) after $72 \mathrm{~h}$. Data are represented as a mean ratio of invading or migrated $\mathrm{GH} 3$ cells towards TAF-CM or F-CM in relation to invading or migrated $\mathrm{GH} 3$ cells in serum-medium conditions \pm S.E.M. ${ }^{*},<0.05$, $* *,<0.01$ (one way-ANOVA with Bonferroni multiple comparison test). levels of CCL2, CCL11, VEGF-A, CCL22, IL-6, FGF-2 and IL-8 in TAF supernatants. CCL2 levels were higher in supernatants from fibroblasts originating from tumours with more proliferation and more capillaries, suggesting a role for TAF-derived CCL2 in PitNET aggressiveness and angiogenesis. CCL2 has a number of roles, including in immune cell chemotaxis, angiogenesis, tumour proliferation and invasion (Yadav et al. 2010). While CCL2 has not previously been described in PitNETs, cell culture supernatants and lysates of human craniopharyngiomas show CCL2 release (Nie et al. 2017). The reason for the gender difference in CCL2 secretion is unclear as no gender-specific effect has previously been described for CCL2 release (Arakelyan et al. 2005, Wu et al. 2017a).

Chemokines and growth factors, such as PDGF (Heldin 2013, Wu et al. 2013), often secreted by TAFs or other non-tumoural cells of the tumour microenvironment, are able to induce EMT, a process whereby tumour cells are reprogrammed to a mesenchymal phenotype acquiring a migratory and invasive characteristics by losing epithelial polarity and adhesion molecules, in particular E-cadherin (Lee et al. 2006, Thiery et al. 2009, De Craene \& Berx 2013). In our study, TAF-derived PDGF-AA levels were negatively correlated with E-cadherin expression, suggesting a possible role for the TAF secretome in promoting EMT in PitNETs, in line with our in vitro experiments findings.

IL-6 plays a role in progression and aggressiveness of PitNETs (Jones et al. 1994, Velkeniers et al. 1994, Arzt et al. 1999, Kurotani et al. 2001, Haedo et al. 2009). Invasive PitNETs have a high proportion of IL-6 expression (67.5\%), while non-invasive PitNETs expressed IL-6 only in $22.5 \%$ of cases (Wu et al. 2016). Suppression of
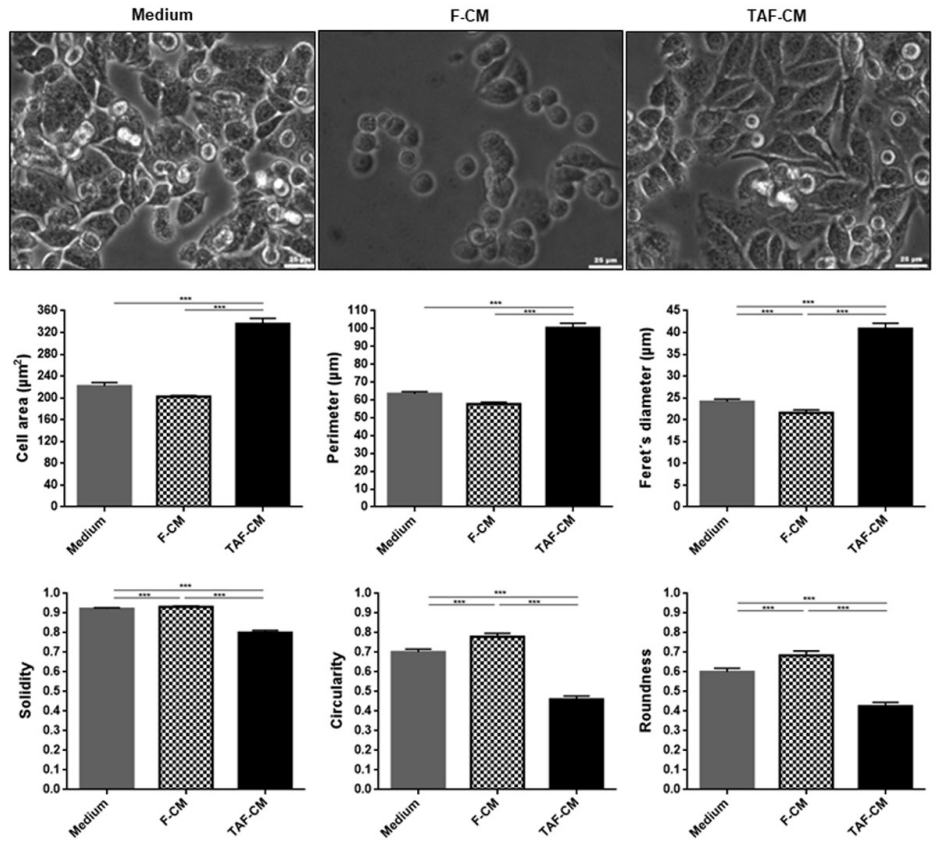

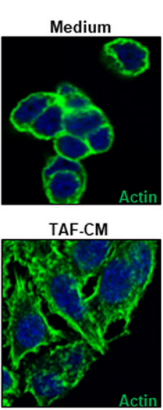

\section{Figure 4}

Morphology of GH3 cells after treatment for $72 \mathrm{~h}$ with serum-medium $(n=3)$, tumour-associated fibroblasts-conditioned medium (TAF-CM) $(n=4)$ and with conditioned medium from dermal fibroblasts from healthy individuals (F-CM) $(n=3)$. GH3 cell morphology was evaluated for six parameters: cell area, Feret's diameter, solidity, perimeter, roundness and circularity. Data are shown as mean \pm S.E.M. for the morphological parameters evaluated. Seventy-five cells were analysed per experiment, with a minimum of three experiments per treatment condition. Scale bar: $25 \mu \mathrm{m}$. ***, <0.001 (two-way ANOVA with Bonferroni multiple comparison test). On the right side is shown alterations on actin fibers in $\mathrm{GH} 3$ cells after treatment with TAF-CM for $72 \mathrm{~h}$ in comparison to complete medium (63x) magnification; DAPI was used to stain the nuclei. 

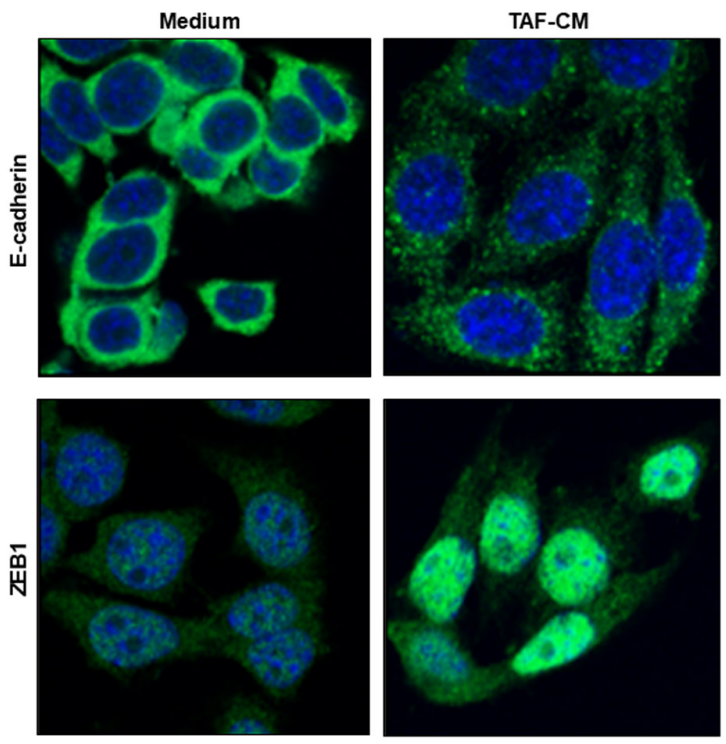

the cytokine transducer gp130, which usually results in inhibition of IL-6 secretion, impaired the development of transplanted GH3 cell tumours in nude mice (Castro et al. 2003). In GH3 cells, IL-6 stimulates cell proliferation and DNA synthesis, as well as GH and prolactin release (Arzt et al. 1993). IL-6 can also be secreted by non-tumoural folliculo-stellate cells, which can have paracrine effect on pituitary tumour cells causing increased proliferation and aggressiveness (Renner et al. 1998, Haedo et al. 2009, Sapochnik et al. 2017a,b). Our study shows that TAFderived IL-6 levels were higher in PitNETs with cavernous sinus invasion, supporting a possible role for the paracrine effects of IL-6 on pituitary tumour invasiveness. Thus, IL-6 may represent a drug target for PitNETs to reduce the paracrine effects of TAFs.

Our in vitro data showed that TAF-derived factors, but not normal skin fibroblasts factors, are able to induce numerous effects on GH3 cells. Direct induction of EMT, in line with increased invasion, migration and altered cell shape, suggest that TAF-derived factors interact with pituitary tumour cells to influence their behaviour and invasiveness. We noted a non-significant trend for increased GH3 cell migration towards skin fibroblast-CM, less marked than in the presence of TAF-CM, which is not surprising considering that skin fibroblasts are also a source of cytokines and chemokines (Kubo \& Kuroyanagi 2005, Nolte et al. 2008), suggesting that fibroblast factors in general may alter tumour cell migration. However, invasion requires not only the capacity for cells to migrate, but also their ability to secrete enzymes to degrade Matrigel (Kramer et al. 2013, Benton et al. 2014); this seems to be induced only by TAF-derived factors and not by factors derived from normal skin fibroblasts. In fact, skin fibroblast-CM was not able to increase invasion, whereas TAF-CM remarkably increased GH3 cell invasion in comparison to complete medium, and almost significantly in comparison to skin fibroblast-CM. The EMT induction by TAF-derived factors, a crucial process for migration and invasion of neoplastic cells (De Craene \& Berx 2013), support the human data linking cavernous sinus invasion and TAF-derived cytokines, particularly IL-6, an interleukin of high importance for fibroblasts biology (Kinoshita et al. 2013, Nagasaki et al. 2014).

Somatostatin controls hormone secretion and proliferation in normal and neoplastic pituitary and reduced IL- 6 and IL-8 in human somatotropinoma cultures (Thiele et al. 2003, Vindelov et al. 2011). Somatostatin's inhibitory effect on IL-6 secretion was also shown in nonpituitary cells (Grimaldi et al. 1997, Andoh et al. 2002,

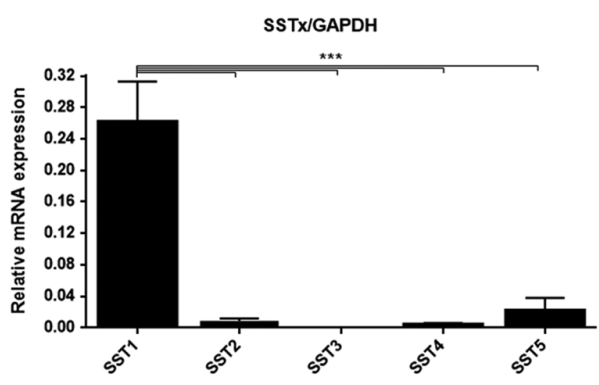

Figure 6

SST expression profile in human PitNET-derived tumour-associated fibroblasts determined by RT-qPCR. Data are shown as relative SSTX mRNA fold change expression to GAPDH \pm S.E.M., determined by RT-qPCR using the standard curve method. $n=16 . * * *,<0.001$ (one way-ANOVA with Bonferroni multiple comparison test). 


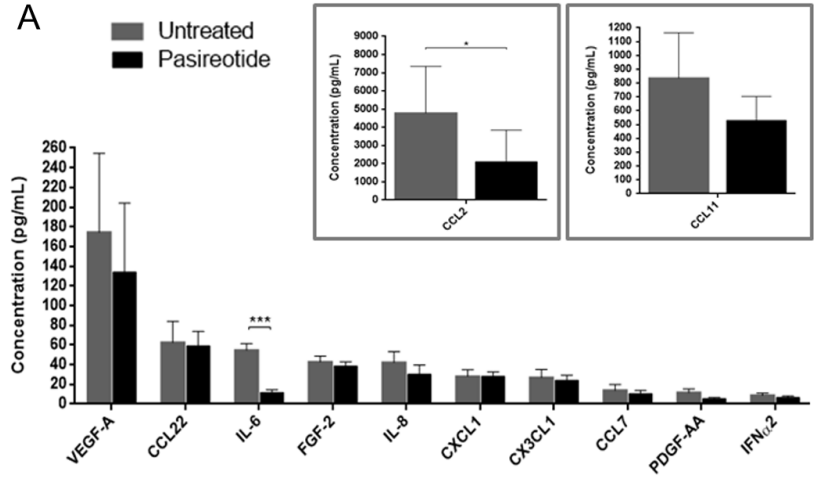

Spangelo et al. 2004). In a study using human NF-PitNET primary cultures, it was demonstrated that pasireotide can inhibit tumour cell viability by inhibiting VEGF secretion (Zatelli et al. 2007). Pasireotide, by activating SST1 expressed in pancreas cancer-associated fibroblasts, inhibits various cytokines including IL-6, with abrogation of metastasis and prevention of EMT (Duluc et al. 2015, Moatassim-Billah et al. 2016). The inhibitory effect of pasireotide on IL-6 secretion from PitNET-derived TAFs that we observed suggests that this effect may play a role in the clinical effectiveness of pasireotide. Furthermore, the benefits of targeting TAFs with pasireotide probably extends beyond its role in inhibiting cytokine release. Fibroblasts are mediators of fibrosis due to their ability to secrete collagen, hyaluronan, proteoglycans and other extracellular matrix-related proteins (Kalluri \& Zeisberg 2006, Cirri \& Chiarugi 2012). A correlation between collagen-producing cell number and fibrous deposition degree was seen in PitNETs, with thyrotrophinomas displaying the highest number of collagen-producing cells and fibrous matrix (Tofrizal et al. 2016), in line with their recognised firm consistency (Yamada et al. 2014) which may hinder surgical resection (Chentli \& Safer-Tabi 2015). Thus, a drug able to target TAFs and reduce the fibrotic process may be valuable in improving outcomes in patients with PitNETs. Emerging data support the antifibrotic properties of somatostatin analogues, mainly through the inhibition of fibroblast proliferation and induction of fibroblast apoptosis (Priestley et al. 1994, Pasquali et al. 2000, Borie et al. 2008). Pasireotide has been recently shown to be as effective as methylprednisolone in improving clinical outcomes in patients with Graves' orbitopathy (Le Moli et al. 2018), a condition in which SSTexpressing orbital fibroblasts are key pathophysiological elements (Priestley et al. 1994, Pasquali et al. 2000).

The anti-secretory and anti-proliferative effects of a specific somatostatin analogue in a certain PitNET

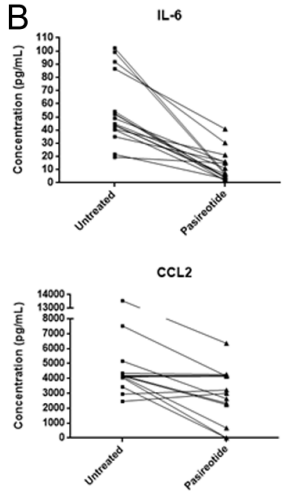

Figure 7

Cytokine secretome from human PitNET-derived tumour-associated fibroblasts at baseline (untreated) and after treatment with pasireotide $\left(10^{-7} \mathrm{M}\right)$. Data are shown in concentration (pg/ $\mathrm{mL}) \pm$ S.E.M. for the top 12 highly secreted cytokines/chemokines/growth factors in PitNET-derived TAF supernatants collected following 24-h serum-free medium conditions with pasireotide $\left(10^{-7} \mathrm{M}\right)$ or without (untreated) (A). IL-6 and CCL2 levels before (left side, square mark) and after pasireotide treatment (right side, triangle mark) are shown per case individually (B). ${ }^{*},<0.05, * * *,<0.001$ (Mann-Whitney $U$ test).

depends on its SST expression pattern and the SST binding profile of that somatostatin analogue (Iacovazzo et al. 2016, Ibanez-Costa et al. 2016, Ibanez-Costa \& Korbonits 2017). However, the mere abundance of a given SST does not necessarily correlate with the level of response to a somatostatin analogue with strong affinity for that SST (Ibanez-Costa et al. 2016). In fact, some studies found no correlation between inhibitory effects of octreotide or pasireotide and a particular SST expression pattern or even less prominent responses of pasireotide in pituitary neoplastic cells expressing high levels of SST5 (IbanezCosta et al. 2016, Gatto et al. 2017). The reasons for such discrepancies are still unknown, but may well be related to extrapituitary effects, such as the modulatory effect of somatostatin analogues directly on non-tumoural cells present in the tumour microenvironment including TAFs. The pharmacological effect on TAFs might also explain why pasireotide efficacy in vivo is superior to octreotide in patients with acromegaly (Colao et al. 2014, Gadelha et al. 2014), while in vitro pasireotide and octreotide similarly inhibit pituitary tumour cells (Ibanez-Costa et al. 2016, Gatto et al. 2017), or the contradictory observations in NF-PitNETs in which octreotide was able to stabilise tumour size in most patients (Fusco et al. 2012), whereas in vitro there was a poor response or even a paradoxical increase in cell viability after treatment with both octreotide and pasireotide (Ibanez-Costa et al. 2016).

The limitations of our study include the fact that we studied only a small cohort of cases with a relatively short postoperative follow-up, as this study is based on fresh primary cell culture, rendering data on longer term clinical outcomes and recurrence unavailable. Our cytokine array experiments lack fresh fibroblasts derived from normal pituitary as controls, we used an alternative suitable control - normal skin fibroblasts. In our in vitro experiments we used a rat pituitary tumour cell line rather than a human cell line, as a human pituitary tumour cell line does not exist. (c) 2019 Society for Endocrinology Published by Bioscientifica Ltd. Printed in Great Britain 
In summary, our data suggest that TAFs, as part of the PitNET tumour microenvironment, represent a source of cytokines influencing tumour proliferation, invasiveness, and neovascularisation, with IL-6 and CCL2 emerging as possible key mediators. Dedicated functional studies are needed to confirm the direct involvement of TAFderived IL-6 and CCL2 in PitNET invasiveness. We have shown that TAF-conditioned medium, but not normal skin fibroblast medium, induces EMT-like morphological changes, downregulates E-cadherin and upregulates ZEB1 expression, and increases the migration and invasion of GH3 cells. We suggest that the inhibitory effects of pasireotide on cytokine release from TAFs may play a key role in its anti-tumoural effects.

\section{Supplementary data}

This is linked to the online version of the paper at https://doi.org/10.1530/ ERC-19-0327.

\section{Declaration of interest}

The authors declare that there is no conflict of interest that could be perceived as prejudicing the impartiality of the research reported.

\section{Funding}

P M was supported by the Joan Adams Clinical Fellowship and the Barts and The London Charity Clinical Research Training Fellowship. M K had Medical Research Council (UK) funding to support to study familial isolated pituitary adenomas.

\section{Acknowledgements}

The authors are grateful to Edwin Garcia (William Harvey Research Institute, Queen Mary University of London, UK) for skillful technical assistance with the isolation of pituitary neuroendocrine tumour-associated fibroblasts. They are grateful to Leo Guasti (William Harvey Research Institute, Queen Mary University of London, UK) for the human skin fibroblasts. They are indebted to Federico Roncaroli (Manchester, UK) for the critical review of this manuscript. They acknowledge the expert care of colleagues involved in the care of the patients participating in the study, including endocrinologists (Stephanie Baldeweg, University College Hospital, London, UK, William M Drake and Scott A Akker, St. Bartholomew's Hospital, London, UK), neuropathologist (Sebastian Brander, Institute of Neurology, London, UK), neuroradiologist (Jane Evanson, St Bartholomew's Hospital, London, UK), and pituitary nurse specialist (Marianna Shiafkou (St Bartholomew's Hospital, London, UK)). They are grateful for the patients involved in the study.

\section{References}

Andoh A, Hata K, Shimada M, Fujino S, Tasaki K, Bamba S, Araki Y, Fujiyama Y \& Bamba T 2002 Inhibitory effects of somatostatin on tumor necrosis factor-alpha-induced interleukin-6 secretion in human pancreatic periacinar myofibroblasts. International Journal of Molecular Medicine 10 89-93. (https://doi.org/10.3892/ijmm.10.1.89)
Arakelyan A, Petrkova J, Hermanova Z, Boyajyan A, Lukl J \& Petrek M 2005 Serum levels of the MCP-1 chemokine in patients with ischemic stroke and myocardial infarction. Mediators of Inflammation 2005 175-179. (https://doi.org/10.1155/MI.2005.175)

Arzt E, Buric R, Stelzer G, Stalla J, Sauer J, Renner U \& Stalla GK 1993 Interleukin involvement in anterior pituitary cell growth regulation: effects of IL-2 and IL-6. Endocrinology 132 459-467. (https://doi. org/10.1210/endo.132.1.8419142)

Arzt E, Pereda MP, Castro CP, Pagotto U, Renner U \& Stalla GK 1999 Pathophysiological role of the cytokine network in the anterior pituitary gland. Frontiers in Neuroendocrinology 20 71-95. (https://doi. org/10.1006/frne.1998.0176)

Balkwill FR 2012 The chemokine system and cancer. Journal of Pathology 226 148-157. (https://doi.org/10.1002/path.3029)

Balkwill FR \& Mantovani A 2012 Cancer-related inflammation: common themes and therapeutic opportunities. Seminars in Cancer Biology 22 33-40. (https://doi.org/10.1016/j.semcancer.2011.12.005)

Balkwill FR, Capasso M \& Hagemann T 2012 The tumor microenvironment at a glance. Journal of Cell Science 125 5591-5596. (https://doi.org/10.1242/jcs.116392)

Barry S, Carlsen E, Marques P, Stiles CE, Gadaleta E, Berney DM, Roncaroli F, Chelala C, Solomou A, Herincs M, et al. 2019 Tumor microenvironment defines the invasive phenotype of AIP-mutationpositive pituitary tumors. Oncogene 38 5381-5395. (https://doi. org/10.1038/s41388-019-0779-5)

Benton G, Arnaoutova I, George J, Kleinman HK \& Koblinski J 2014 Matrigel: from discovery and ECM mimicry to assays and models for cancer research. Advanced Drug Delivery Reviews 79-80 3-18. (https:// doi.org/10.1016/j.addr.2014.06.005)

Bissell MJ \& Radisky D 2001 Putting tumours in context. Nature Reviews: Cancer 1 46-54. (https://doi.org/10.1038/35094059)

Borie R, Fabre A, Prost F, Marchal-Somme J, Lebtahi R, MarchandAdam S, Aubier M, Soler P \& Crestani B 2008 Activation of somatostatin receptors attenuates pulmonary fibrosis. Thorax $\mathbf{6 3}$ 251-258. (https://doi.org/10.1136/thx.2007.078006)

Castro CP, Giacomini D, Nagashima AC, Onofri C, Graciarena M, Kobayashi K, Paez-Pereda M, Renner U, Stalla GK \& Arzt E 2003 Reduced expression of the cytokine transducer gp130 inhibits hormone secretion, cell growth, and tumor development of pituitary lactosomatotrophic GH3 cells. Endocrinology 144 693-700. (https:// doi.org/10.1210/en.2002-220891)

Chentli F \& Safer-Tabi A 2015 Pituitary stone or calcified pituitary tumor? Three cases and literature review. International Journal of Endocrinology and Metabolism 13 e28383. (https://doi.org/10.5812/ ijem.28383v2)

Cirri P \& Chiarugi P 2012 Cancer-associated-fibroblasts and tumour cells: a diabolic liaison driving cancer progression. Cancer Metastasis Reviews 31 195-208. (https://doi.org/10.1007/s10555-011-9340-x)

Colao A, Bronstein MD, Freda P, Gu F, Shen CC, Gadelha M, Fleseriu M, Van Der Lely AJ, Farrall AJ, Hermosillo Resendiz K, et al. 2014 Pasireotide versus octreotide in acromegaly: a head-to-head superiority study. Journal of Clinical Endocrinology and Metabolism 99 791-799. (https://doi.org/10.1210/jc.2013-2480)

De Boeck A, Hendrix A, Maynard D, Van Bockstal M, Daniels A, Pauwels P, Gespach C, Bracke M \& De Wever O 2013 Differential secretome analysis of cancer-associated fibroblasts and bone marrowderived precursors to identify microenvironmental regulators of colon cancer progression. Proteomics 13 379-388. (https://doi. org/10.1002/pmic.201200179)

De Craene B \& Berx G 2013 Regulatory networks defining EMT during cancer initiation and progression. Nature Reviews: Cancer 13 97-110. (https://doi.org/10.1038/nrc3447)

Di Ieva A, Rotondo F, Syro LV, Cusimano MD \& Kovacs K 2014 Aggressive pituitary adenomas - diagnosis and emerging treatments. Nature Reviews: Endocrinology 10 423-435. (https://doi.org/10.1038/ nrendo.2014.64) https://erc.bioscientifica.com

https://doi.org/10.1530/ERC-19-0327 (c) 2019 Society for Endocrinology Published by Bioscientifica Ltd. Printed in Great Britain 
Duluc C, Moatassim-Billah S, Chalabi-Dchar M, Perraud A, Samain R, Breibach F, Gayral M, Cordelier P, Delisle MB, BousquetDubouch MP, et al. 2015 Pharmacological targeting of the protein synthesis mTOR/4E-BP1 pathway in cancer-associated fibroblasts abrogates pancreatic tumour chemoresistance. EMBO Molecular Medicine 7 735-753. (https://doi.org/10.15252/emmm.201404346)

Fusco A, Giampietro A, Bianchi A, Cimino V, Lugli F, Piacentini S, Lorusso M, Tofani A, Perotti G, Lauriola L, et al. 2012 Treatment with octreotide LAR in clinically non-functioning pituitary adenoma: results from a case-control study. Pituitary 15 571-578. (https://doi.org/10.1007/s11102-011-0370-8)

Gadelha MR, Bronstein MD, Brue T, Coculescu M, Fleseriu M, Guitelman M, Pronin V, Raverot G, Shimon I, Lievre KK, et al. 2014 Pasireotide versus continued treatment with octreotide or lanreotide in patients with inadequately controlled acromegaly (PAOLA): a randomised, phase 3 trial. Lancet: Diabetes and Endocrinology 2 875-884. (https://doi.org/10.1016/S2213-8587(14)70169-X)

Gatto F, Feelders RA, Franck SE, Van Koetsveld PM, Dogan F, Kros JM, Neggers SJCMM, Van Der Lely AJ, Lamberts SWJ, Ferone D, et al. 2017 In vitro head-to-head comparison between octreotide and pasireotide in GH-secreting pituitary adenomas. Journal of Clinical Endocrinology and Metabolism 102 2009-2018. (https://doi. org/10.1210/jc.2017-00135)

Grimaldi M, Florio T \& Schettini G 1997 Somatostatin inhibits interleukin 6 release from rat cortical type I astrocytes via the inhibition of adenylyl cyclase. Biochemical and Biophysical Research Communications 235 242-248. (https://doi.org/10.1006/ bbrc.1997.6513)

Grizzi F, Borroni EM, Vacchini A, Qehajaj D, Liguori M, Stifter S, Chiriva-Internati M \& Di Ieva A 2015 Pituitary adenoma and the chemokine network: a systemic view. Frontiers in Endocrinology 6141. (https://doi.org/10.3389/fendo.2015.00141)

Gunther T, Tulipano G, Dournaud P, Bousquet C, Csaba Z, Kreienkamp HJ, Lupp A, Korbonits M, Castano JP, Wester HJ, et al. 2018 International Union of Basic and Clinical Pharmacology. CV. Somatostatin receptors: structure, function, ligands, and new nomenclature. Pharmacological Reviews 70 763-835. (https://doi. org/10.1124/pr.117.015388)

Haedo MR, Gerez J, Fuertes M, Giacomini D, Paez-Pereda M, Labeur M, Renner U, Stalla GK \& Arzt E 2009 Regulation of pituitary function by cytokines. Hormone Research 72 266-274. (https://doi. org/10.1159/000245928)

Heldin CH 2013 Targeting the PDGF signaling pathway in tumor treatment. Cell Communication and Signaling 11 97. (https://doi. org/10.1186/1478-811X-11-97)

Iacovazzo D, Carlsen E, Lugli F, Chiloiro S, Piacentini S, Bianchi A, Giampietro A, Mormando M, Clear AJ, Doglietto F, et al. 2016 Factors predicting pasireotide responsiveness in somatotroph pituitary adenomas resistant to first-generation somatostatin analogues: an immunohistochemical study. European Journal of Endocrinology 174 241-250. (https://doi.org/10.1530/EJE-15-0832)

Ibanez-Costa A \& Korbonits M 2017 AIP and the somatostatin system in pituitary tumours. Journal of Endocrinology 235 R101-R116. (https:// doi.org/10.1530/JOE-17-0254)

Ibanez-Costa A, Rivero-Cortes E, Vazquez-Borrego MC, Gahete MD, Jimenez-Reina L, Venegas-Moreno E, De La Riva A, Arraez MÁ, Gonzalez-Molero I, Schmid HA, et al. 2016 Octreotide and pasireotide (dis)similarly inhibit pituitary tumor cells in vitro. Journal of Endocrinology 231 135-145. (https://doi.org/10.1530/JOE-16-0332)

Jagannathan J, Smith R, Devroom HL, Vortmeyer AO, Stratakis CA, Nieman LK \& Oldfield EH 2009 Outcome of using the histological pseudocapsule as a surgical capsule in Cushing disease. Journal of Neurosurgery 111 531-539. (https://doi.org/10.3171/2008.8.JNS08339)

Jones TH, Daniels M, James RA, Justice SK, McCorkle R, Price A, KendallTaylor P \& Weetman AP 1994 Production of bioactive and immunoreactive interleukin-6 (IL-6) and expression of IL-6 messenger ribonucleic acid by human pituitary adenomas. Journal of Clinical Endocrinology and Metabolism 78 180-187. (https://doi. org/10.1210/jcem.78.1.8288702)

Kalluri R \& Zeisberg M 2006 Fibroblasts in cancer. Nature Reviews: Cancer 6 392-401. (https://doi.org/10.1038/nrc1877)

Kinoshita H, Hirata Y, Nakagawa H, Sakamoto K, Hayakawa Y, Takahashi R, Nakata W, Sakitani K, Serizawa T, Hikiba Y, et al. 2013 Interleukin-6 mediates epithelial-stromal interactions and promotes gastric tumorigenesis. PLOS ONE 8 e60914. (https://doi.org/10.1371/ journal.pone.0060914)

Kramer N, Walzl A, Unger C, Rosner M, Krupitza G, Hengstschlager M \& Dolznig H 2013 In vitro cell migration and invasion assays. Mutation Research 752 10-24. (https://doi.org/10.1016/j.mrrev.2012.08.001)

Kubo K \& Kuroyanagi Y 2005 A study of cytokines released from fibroblasts in cultured dermal substitute. Artificial Organs 29 845-849. (https://doi.org/10.1111/j.1525-1594.2005.00138.x)

Kurotani R, Yasuda M, Oyama K, Egashira N, Sugaya M, Teramoto A \& Osamura RY 2001 Expression of interleukin-6, interleukin-6 receptor (gp80), and the receptor's signal-transducing subunit (gp130) in human normal pituitary glands and pituitary adenomas. Modern Pathology 14 791-797. (https://doi.org/10.1038/modpathol.3880392)

Le Moli R, Castoro C, Mouritz M \& Souters M 2018 Pasireotide and Graves' orbitopathy: outcome in terms of efficacy compared to parental metilprednisolone: a pilot study. Endocrine Abstracts $\mathbf{5 6}$ 1113. (https://doi.org/10.1530/endoabs.56.p1113)

Lee JM, Dedhar S, Kalluri R \& Thompson EW 2006 The epithelialmesenchymal transition: new insights in signaling, development, and disease. Journal of Cell Biology 172 973-981. (https://doi. org $/ 10.1083 /$ jcb.200601018)

Liao Y, Ni Y, He R, Liu W \& Du J 2013 Clinical implications of fibroblast activation protein-alpha in non-small cell lung cancer after curative resection: a new predictor for prognosis. Journal of Cancer Research and Clinical Oncology 139 1523-1528. (https://doi.org/10.1007/ s00432-013-1471-8)

McKayed KK \& Simpson JC 2013 Actin in action: imaging approaches to study cytoskeleton structure and function. Cells 2 715-731. (https:// doi.org/10.3390/cells2040715)

Moatassim-Billah S, Duluc C, Samain R, Jean C, Perraud A, Decaup E, Cassant-Sourdy S, Bakri Y, Selves J, Schmid H, et al. 2016 Antimetastatic potential of somatostatin analog SOM230: indirect pharmacological targeting of pancreatic cancer-associated fibroblasts. Oncotarget 7 41584-41598. (https://doi.org/10.18632/ oncotarget.9296)

Molitch ME 2017 Diagnosis and treatment of pituitary adenomas: a review. JAMA 317 516-524. (https://doi.org/10.1001/ jama.2016.19699)

Nagasaki T, Hara M, Nakanishi H, Takahashi H, Sato M \& Takeyama H 2014 Interleukin- 6 released by colon cancer-associated fibroblasts is critical for tumour angiogenesis: anti-interleukin-6 receptor antibody suppressed angiogenesis and inhibited tumour-stroma interaction. British Journal of Cancer 110 469-478. (https://doi.org/10.1038/ bjc.2013.748)

Nie J, Huang GL, Deng SZ, Bao Y, Liu YW, Feng ZP, Wang CH, Chen M, Qi ST \& Pan J 2017 The purine receptor P2X7R regulates the release of pro-inflammatory cytokines in human craniopharyngioma. Endocrine-Related Cancer 24 287-296. (https://doi.org/10.1530/ERC16-0338)

Nolte SV, Xu W, Rennekampff HO \& Rodemann HP 2008 Diversity of fibroblasts - a review on implications for skin tissue engineering. Cells, Tissues, Organs 187 165-176. (https://doi. org/10.1159/000111805)

Pasqualato A, Lei V, Cucina A, Dinicola S, D'anselmi F, Proietti S, Masiello MG, Palombo A \& Bizzarri M 2013 Shape in migration: quantitative image analysis of migrating chemoresistant HCT-8 colon cancer cells. Cell Adhesion and Migration 7 450-459. (https:// doi.org/10.4161/cam.26765) https://erc.bioscientifica.com

https://doi.org/10.1530/ERC-19-0327 (c) 2019 Society for Endocrinology Published by Bioscientifica Ltd. Printed in Great Britain 
Pasquali D, Vassallo P, Esposito D, Bonavolonta G, Bellastella A \& Sinisi AA 2000 Somatostatin receptor gene expression and inhibitory effects of octreotide on primary cultures of orbital fibroblasts from Graves' ophthalmopathy. Journal of Molecular Endocrinology 25 63-71. (https://doi.org/10.1677/jme.0.0250063)

Priestley GC, Aldridge RD, Sime PJ \& Wilson D 1994 Skin fibroblast activity in pretibial myxoedema and the effect of octreotide (Sandostatin) in vitro. British Journal of Dermatology 131 52-56. (https://doi.org/10.1111/j.1365-2133.1994.tb08457.x)

Renner U, Gloddek J, Pereda MP, Arzt E \& Stalla GK 1998 Regulation and role of intrapituitary IL- 6 production by folliculostellate cells. Domestic Animal Endocrinology 15 353-362. (https://doi.org/10.1016/ S0739-7240(98)00027-7)

Sapochnik M, Fuertes M \& Arzt E 2017a Programmed cell senescence: role of IL-6 in the pituitary. Journal of Molecular Endocrinology $\mathbf{5 8}$ R241-R253. (https://doi.org/10.1530/JME-17-0026)

Sapochnik M, Haedo MR, Fuertes M, Ajler P, Carrizo G, Cervio A, Sevlever G, Stalla GK \& Arzt E 2017b Autocrine IL-6 mediates pituitary tumor senescence. Oncotarget 8 4690-4702. (https://doi. org/10.18632/oncotarget.13577)

Shiga K, Hara M, Nagasaki T, Sato T, Takahashi H \& Takeyama H 2015 Cancer-associated fibroblasts: their characteristics and their roles in tumor growth. Cancers 7 2443-2458. (https://doi.org/10.3390/ cancers7040902)

Spangelo BL, Horrell S, Goodwin AL, Shroff S \& Jarvis WD 2004 Somatostatin and gamma-aminobutyric acid inhibit interleukin-1 beta-stimulated release of interleukin-6 from rat C6 glioma cells. Neuroimmunomodulation 11 332-340. (https://doi. org/10.1159/000079414)

Takano S, Akutsu H, Hara T, Yamamoto T \& Matsumura A 2014 Correlations of vascular architecture and angiogenesis with pituitary adenoma histotype. International Journal of Endocrinology 2014 989574. (https://doi.org/10.1155/2014/989574)

Taylor DG, Jane JA \& Oldfield EH 2018 Resection of pituitary macroadenomas via the pseudocapsule along the posterior tumor margin: a cohort study and technical note. Journal of Neurosurgery 128 422-428. (https://doi.org/10.3171/2017.7.JNS171658)

Thiele JO, Lohrer P, Schaaf L, Feirer M, Stummer W, Losa M, Lange M, Tichomirowa M, Arzt E, Stalla GK, et al. 2003 Functional in vitro studies on the role and regulation of interleukin- 6 in human somatotroph pituitary adenomas. European Journal of Endocrinology 149 455-461. (https://doi.org/10.1530/eje.0.1490455)

Thiery JP, Acloque H, Huang RY \& Nieto MA 2009 Epithelialmesenchymal transitions in development and disease. Cell $139871-$ 890. (https://doi.org/10.1016/j.cell.2009.11.007)

Tofrizal A, Fujiwara K, Yashiro T \& Yamada S 2016 Alterations of collagenproducing cells in human pituitary adenomas. Medical Molecular Morphology 49 224-232. (https://doi.org/10.1007/s00795-016-0140-9)
Velkeniers B, Vergani P, Trouillas J, D’Haens J, Hooghe RJ \& HooghePeters EL 1994 Expression of IL-6 mRNA in normal rat and human pituitaries and in human pituitary adenomas. Journal of Histochemistry and Cytochemistry 42 67-76. (https://doi. org/10.1177/42.1.8263325)

Vindelov SD, Hartoft-Nielsen ML, Rasmussen ÅK, Bendtzen K, Kosteljanetz M, Andersson AM \& Feldt-Rasmussen U 2011 Interleukin-8 production from human somatotroph adenoma cells is stimulated by interleukin-1beta and inhibited by growth hormone releasing hormone and somatostatin. Growth Hormone and IGF Research 21 134-139. (https://doi.org/10.1016/j.ghir.2011.03.005)

Wu Q, Hou X, Xia J, Qian X, Miele L, Sarkar FH \& Wang Z 2013 Emerging roles of PDGF-D in EMT progression during tumorigenesis. Cancer Treatment Reviews 39 640-646. (https://doi.org/10.1016/j. ctrv.2012.11.006)

Wu JL, Qiao JY \& Duan QH 2016 Significance of TNF-alpha and IL-6 expression in invasive pituitary adenomas. Genetics and Molecular Research 15 [epub]. (https://doi.org/10.4238/gmr.15017502)

Wu M, Baron M, Pedroza C, Salazar GA, Ying J, Charles J, Agarwal SK, Hudson M, Pope J, Zhou X, et al. 2017a CCL2 in the circulation predicts long-term progression of interstitial lung disease in patients With early systemic sclerosis: data from two independent cohorts. Arthritis and Rheumatology 69 1871-1878. (https://doi.org/10.1002/ art.40171)

Wu X, Tao P, Zhou Q, Li J, Yu Z, Wang X, Li J, Li C, Yan M, Zhu Z, et al. $2017 b$ IL-6 secreted by cancer-associated fibroblasts promotes epithelial-mesenchymal transition and metastasis of gastric cancer via JAK2/STAT3 signaling pathway. Oncotarget 8 20741-20750. (https://doi.org/10.18632/oncotarget.15119)

Yadav A, Saini V \& Arora S 2010 MCP-1: chemoattractant with a role beyond immunity: a review. Clinica Chimica Acta 411 1570-1579. (https://doi.org/10.1016/j.cca.2010.07.006)

Yamada S, Fukuhara N, Horiguchi K, Yamaguchi-Okada M, Nishioka H, Takeshita A, Takeuchi Y, Ito J \& Inoshita N 2014 Clinicopathological characteristics and therapeutic outcomes in thyrotropin-secreting pituitary adenomas: a single-center study of 90 cases. Journal of Neurosurgery 121 1462-1473. (https://doi org/10.3171/2014.7.JNS1471)

Yoshimura T 2017 The production of monocyte chemoattractant protein-1 (MCP-1)/CCL2 in tumor microenvironments. Cytokine 98 71-78. (https://doi.org/10.1016/j.cyto.2017.02.001)

Zatelli MC, Piccin D, Vignali C, Tagliati F, Ambrosio MR, Bondanelli M, Cimino V, Bianchi A, Schmid HA, Scanarini M, et al. 2007 Pasireotide, a multiple somatostatin receptor subtypes ligand, reduces cell viability in non-functioning pituitary adenomas by inhibiting vascular endothelial growth factor secretion. Endocrine-Related Cancer 14 91-102. (https://doi. org/10.1677/ERC-06-0026)

Received in final form 16 October 2019

Accepted 23 October 2019

Accepted Preprint published online 23 October 2019 (c) 2019 Society for Endocrinology Published by Bioscientifica Ltd. Printed in Great Britain 